\title{
The Emergence and Perpetuation of a Destructive Culture in an Elite Sport in the United Kingdom
}

This is an Accepted Manuscript version of the following article, accepted for publication in Sport in Society. Niels B. Feddersen, Robert Morris, Martin A. Littlewood \& David J. Richardson (2020) The emergence and perpetuation of a destructive culture in an elite sport in the United Kingdom, Sport in Society, 23:6, 1004-1022, DOI: $10.1080 / 17430437.2019 .1680639$. It is deposited under the terms of the Creative Commons Attribution-NonCommercial License (http://creativecommons.org/licenses/by-nc/4.0/) which permits non-commercial re-use, distribution, and reproduction in any medium, provided the origihal work is properly cited. 

1

2

4

DESTRUCTIVE CULTURE IN SPORT

1 The Emergence and Perpetuation of a Destructive Culture in an Elite 2 Sport in the United Kingdom
Recent inquiries into elite sports in the United Kingdom has unearthed examples
of destructive cultures. Yet, earlier research left destructive cultures overlooked.
The purpose of this article is to (1) outline the process of how a destructive organisational culture emerges and perpetuates in one Olympic sport in the
United Kingdom, and (2) the features that regulate the process. We combined Action Research and Grounded Theory in a 16-month longitudinal study. The primary data collection strategies were ethnography and ten focus groups, with athletes, coaches, parents, and the national governing body (NGB). Twenty-six individual interviews with stakeholders supplemented these. A destructive culture emerged during radical changes, and antagonism in the power relations between the NGB and stakeholders characterised this process. Denial of responsibility and social weighting neutralised the stigma of perpetuating antagonism. In conclusion, sports organisations should be vigilant of how ignoring and denying antagonism could lead to a destructive culture.

Keywords: culture; destructive conflict; elite sports; organisational psychology; sports management 


\section{DESTRUCTIVE CULTURE IN SPORT}

The Emergence and Perpetuation of a Destructive Culture in an Elite Sport in the United Kingdom

Organisational culture used to be an avenue for researching covert power relations and backstage politics. It also used to provide thick analyses of organisational life (Alvesson 2017). It is a field that is very much alive in contemporary research. Yet, it is also a very divisive field of inquiry (Mcdougall et al. 2017; Alvesson 2017). In academia, it serves as a vehicle for interest in the symbolic dimensions of organisational life and processes of meaning-making. And for practitioners, culture serves as a toolkit for creating commitment and transforming underperforming or destructive cultures (Cruickshank and Collins 2012).

The normative approach to understanding organisational culture in sports has been to conceptualise it through a performance enhancement lens (cf. Maitland, Hills, and Rhind 2015; Cruickshank, Collins, and Minten 2014, 2015). It has been identified as having a significant influence on talent development (see Henriksen and Stambulova 2017; Henriksen, Stambulova, and Roessler 2010a, 2011, 2010b), developing a highperformance culture (see Henriksen 2015), performance outcomes at the Olympic Games (see Gould et al. 2002; Greenleaf, Gould, and Dieffenbach 2001), and performance leadership (see Fletcher and Arnold 2011).

A recent review by Wagstaff and Burton-Wylie (2018) observe that upwards of seventy per cent of sport research studies culture through an integration lens. Using the integration paradigm centres on the functionality of a culture (cf. Fletcher and Arnold 2011; Henriksen 2015; Cruickshank, Collins, and Minten 2013). Culture is thus an integration mechanism that teaches new members an agreed upon set of appropriate behaviours (Schein 2010). Success or a high-performing culture is, therefore, characterised by a unified and robust culture (Henriksen 2015). Schein (2010) details 


\section{DESTRUCTIVE CULTURE IN SPORT}

45 that this paradigm assumes that a leader's values are a master blueprint for an organisation's culture. In doing so, it delivers culture as a variable that can be manipulated at the discretion of a charismatic leader.

Nevertheless, recent management research (e.g. Alvesson 2017; Helin et al. 2014) has criticised this line of inquiry. This frustration is because only focusing on what is shared tends to exacerbate much of the profound cultural understanding. Alvesson (2017) highlights that organisational practitioners are often let down by the inadequacies of this superficial understanding. Reducing culture to a consensus-based system (see Wagstaff and Burton-Wylie 2018) does tend to deny ambiguity and inconsistencies (Mannion and Davies 2016). This superficial line of inquiry has even led some researchers to comment on organisational culture as a field which is 'intellectually dead' (see Alvesson 2017; Wagstaff and Burton-Wylie 2018). We propose to dive underneath the surface of organisational culture (see Alvesson 2017; Helin et al. 2014) and consider the backstage processes. In denying ambiguity, research in sport has tended to overlook the harmful characteristics of organisational cultures. One reason might be that the integration perspective only considers shared aspects (Maitland, Hills, and Rhind 2015). Yet, athletes are often commodified in win-at-all-costs cultures (Mountjoy 2018). Current research has considered organisational culture as a source of strain for athletes (Arnold, Fletcher, and Daniels 2013); underpinning unsuccessful talent development environments (Henriksen, Larsen, and Christensen 2014); and cultures that deny, ignore, and accept abuse (Mountjoy 2018). This latter consideration came in the wake of the Nassar abuse scandal (Daniels 2017). Other global examples of destructive cultures include a culture of not counting the [human] costs in Australian cricket (The Ethics Centre 2018), and allegations of a culture of bullying in the United Kingdom (Grey-Thompson 2017). 


\section{DESTRUCTIVE CULTURE IN SPORT}

0 Some might dismiss these as extreme cases. Yet, the Culture Health Check carried out

by UK Sport (2018) stated that there is a 'need to address unacceptable behaviour in the

72 High Performance System' (p. 14). These applied concerns shed light on the

73 controversy of how athletes and those who work in sports are treated (Grey-Thompson 2017).

Many wishes these phenomena did not exist. Yet, the sports sector is under more scrutiny than ever before. Earlier research has neglected destructive cultures by denying ambiguity. But, authors have also highlighted a common thread referring to the organisational culture of the organisations involved and the potential institutional culpability (see McCradden and Cusimano 2018; Grey-Thompson 2017; Daniels 2017). It is, therefore, prompt to consider the less desirable aspects of organisational culture.

Especially those cultures that have destructive features to them (Grey-Thompson 2017; Mountjoy 2018).

\section{Researching Destructive Organisational Culture Processes}

This article is a part of a more extensive longitudinal study into a change of culture in one sport in the United Kingdom. Building on Alvesson (2017), we seek to illuminate cultural processes as-they-happen. Building on Mannion and Davies (2016) we define culture as a dynamic process of negotiating values and beliefs that, for a time, provides problems and solutions to a defined group. This definition frames this study by taking the position that organisations are cultures. Doing so treats organisational culture as a metaphor of organisation. Meyerson and Martin (1987) explains that this view emphasises inconsistencies and disagreements rather than consensus. Moreover, this position stresses 'the importance of various subunits including groups and individuals' (Meyerson and Martin 1987, 630). An organisation is simply an arbitrary boundary 


\section{DESTRUCTIVE CULTURE IN SPORT}

around a collection of subcultures. The unique features of organisational culture are, therefore, how subcultures meet in negotiating values and beliefs (Meyerson and Martin 1987). Moreover, how this process can influence diversity, ambiguity, and conflict in progressive and/or destructive ways.

Subcultures are groups within an organisational culture. These can have overlapping, at variance, or ambivalent features with those of the broader culture (Mannion and Davies 2016). Accordingly, subcultures might represent orthogonal subcultures that tacitly accepts another subculture (Mannion and Davies 2016).

Subcultures might be counter subcultures representing disagreements leading to conflict or antagonism. Alternatively, enhancing subcultures. These might appear as a response to changes that are more fervent to their dynamic process of negotiating culture. Thus amplifying and supporting other subcultures (Mannion and Davies 2016).

The unique contribution of this article is that we illuminate the cultural process of the emergence and perpetuation of a destructive culture. Researching destructive cultures is a chasm in academic research. So, we need a lens through which we can start to understand what constitutes a destructive culture. We propose that legitimacy may be a favourable lens. Pfarrer, DeCelles, Smith, and Taylor (2008) suggest that legitimacy is a general perception of an individual's or organisation's actions as appropriate within a socially constructed system. Since organisations can have different perceptions of what is socially desirable behaviours based on their characteristics, legitimacy originates in a relationship between broader societal norms and the culture in the organisation (cf.

Pfarrer et al. 2008). A destructive culture violates legitimacy through enacting behaviours violating broader societal norms and standards of conduct (Pfarrer et al. 2008). Examples are a culture enacting behaviours such as fear, intimidation, and 


\section{DESTRUCTIVE CULTURE IN SPORT}

19 power relationships are abused; and this abuse is denied, ignored, and even the norm

20 (Mountjoy 2018; McCradden and Cusimano 2018). Also, Grey-Thompson (2017)

121 illustrates the relationship between broader social norms and culture by explaining:

122 '[s]port cannot think of itself as special or different and able to behave outside what are considered acceptable behaviour patterns' (p. 4). Researching destructive cultures

against this backdrop is a critical addition to the literature. The purpose of this article is to (1) outline the process of how a destructive organisational culture emerges and perpetuates in one Olympic sport in the United Kingdom, and (2) the features that regulate the process.

\section{Methodology}

This study adopts an approach integrating Action Research (AR) and Grounded Theory Methodology (GT) (Dick 2007; Teram, Schachter, and Stalker 2005). AR focuses on

31 change and collaboration with participants on finding solutions to unwanted conditions

132 (see Gergen 2015). And GT focuses on unravelling process-as-it-happens (see Corbin

133 and Strauss 2015). Integrating these allows us to understand the participative reality of change processes (Dick 2007; Heron and Reason 2006). Henceforth, we will adopt the term Grounded Action to describe this integrated method. We continue by outlining the data collection strategies before showing the entanglements of the on-going iterative analysis and rigour. The rigour of this study is underpinned by the epistemology of the Participatory Inquiry Paradigm (see Heron and Reason 1997). This paradigm sets the tone for how we engaged participants in the research. Besides how the iterative analysis helped to unravel process along the way. 


\section{DESTRUCTIVE CULTURE IN SPORT}

\section{Data Collection Strategies}

142 In adopting a participatory approach, we chose ethnographic observations as the

143 primary data collection approach and focus group interviews as the secondary strategy.

144 We did so to bring collaboration and dialogue to the forefront of the study (Heron and

145 Reason 2006). We supplemented these two approaches with semi-structured interviews 146 and analysis of documents.

\section{Ethnographic observations.}

148 The first author was embedded in a National Governing Body (NGB) as a critical friend

149 (e.g. providing a mirror, asking provocative questions, and providing helpful critiques)

150 for sixteen months. This role included extensive fieldwork to illuminate events as they

151 unfolded (Krane and Baird 2005; Costa and Kallick 1993). These events happened at

152 the department, inter-department, and organisational meetings at the offices of the NGB,

153 Youth National Team camps, Coach Development courses, competitions, public events, 154 and staff outings. Extensive field notes were expressed in memos and diagrams, which

155 is in line with core GT elements (see Holt 2016).

156 Focus group interviews.

157 The first-author carried out ten focus groups lasting from 40 - 130 minutes (Table 1).

158 These aimed at engaging participants in dialogue to explore the different narratives and

159 being sensitive to the interpersonal communication to highlight subcultural

160 understandings (Kitzinger 1995). The first focus group was with the Talent Team (see

161 Reconnaissance). This discussion aimed at identifying essential stakeholders and critical

162 areas of inquiry (e.g. what do I need to know to understand your sport? What is the

163 history of your sport?). Doing so grouped other participants (Parents of Athletes, 


\section{DESTRUCTIVE CULTURE IN SPORT}

Coaches, Athletes aged 18-23; Table 1) to identify key areas for the ethnography (e.g. what should I notice about your sport?).

\section{Semi-structured interviews.}

This study also included twenty-six semi-structured individual interviews (35-75 min; Brinkmann and Kvale 2018). These probed perceptions of the elite sports context, the emergence of antagonism, and how inside and outside factors influenced the process. The Talent Team and the first-author developed the interview guides from field notes, open coding, and data from the focus groups (Brinkmann and Kvale 2018). We identified participants via theoretical sampling (see procedure).

\section{Documents.}

We collected documents and web pages to garner contextual depth of the NGB and the community of the sport. Documents included training programmes, official papers describing the mission and structure of the NGB, and public communication documents.

\section{Procedure, Analysis, and Rigor}

Five NGBs were contacted via email in May 2017 after obtaining ethical approval. The first-author held phone meetings with three respondents. We agreed with one NGB to take part. So, the present study was carried out from July 2017 - November 2018. In understanding organisations as cultures (see Meyerson and Martin 1987), we define the organisational culture under study as an organisation consisting of an NGB of a multievent sport, and the community within the sport. This sport is a longstanding part of the 

187 in the findings section. paymasters' (p. 9).

\section{Grounded Action Cycles}

\section{Reconnaissance}

\section{DESTRUCTIVE CULTURE IN SPORT}

individuals are anonymous. Yet, we strive to provide a vivid description of the context

Meyerson and Martin (1987) also emphasise the salience of influences from outside the organisation. We will therefore also consider the governance relevant to talent development in the UK. This context includes a plurality of support agencies (see

Grix and Phillpots 2011). Including the English Institute of Sport (EIS) that provides sport science and medical support services; the Talented Athlete Scholarship Scheme (TASS), which is a partnership between talented athletes, education institutions, and NGBs supporting dual-career athletes; and UK Coaching, which supports coach development. Rather than having a dispersed funding system through a plurality of agencies, it is concentrated around two organisations, Sport England and UK Sport (cf.

Houlihan \& Green, 2009). Grix and Phillpots (2011) explain that the influence of this is that: 'most National Governing Bodies of sport (NGBs) are hidebound to their

Figure 1 summarises the participatory Grounded Action process. The procedure included a reconnaissance phase and four double-cycles of an implementation and monitoring phase, and a reflection and review phase.

[Please insert Figure 1 near here]

The reconnaissance lasted from July 2017 - November 2017. It aimed to establish an understanding of the context with the view to identify later collaboration (Gilbourne \& Richardson, 2005). The first step was to negotiate consent for the longitudinal study (Iphofen 2013). Following this, we established a research group to integrate a group of 


\section{DESTRUCTIVE CULTURE IN SPORT}

participants as co-researchers throughout the study (Kildedal and Laursen 2014). We label this group the Talent Team. It consisted of the Talent Manager, the Head of Coach Development, the Talent Administrator, and the first author. During this process, we agreed that the first-author should act as a critical friend in the Talent Team to provide a mirror (Costa and Kallick 1993; Duus et al. 2014). The Assistant Talent Manager and the Head Talent Coach were recruited into the group in September 2017. This group oversaw talent development and the senior elite programme. Our ambition was to move participants from being passive vessels to engage them into dialogue on what was meaningful in their context (Sbaraini et al. 2011).

The first author began open coding as soon as the first data was collected. This process focused on describing the preconditions and agreeing on a meaningful future state (Holt 2016). Memo-writing as well as introducing the conditional/consequential matrix and the paradigm aided the process (Kelle 2007; Corbin and Strauss 2015). All concepts were discussed in the Talent Team. We identified anomalies during this collaborative process. Anomalies included athletes in underserved areas (Theoretical sampling 1) and how external stakeholders influenced the outside conditions. These stakeholders included other NGBs, and the following Governing Sports Organisations (GSO): UK Sport, Sport England, UK Coaching, EIS, TASS, and a University Sports Programme (Theoretical sampling 2; Table 1). Each participant in Theoretical sampling 2 took part in two individual Skype interviews. We allowed for at least two months between the first and second interview to increase the contextual depth and help to explore the fluid nuances of culture change (Culver 2012; Maitland, Hills, and Rhind 2015). Using Skype eased geographical constraints and the hectic schedules of upperechelon employees (Deakin and Wakefield 2014; Janghorban, Roudsari, and Taghipour 


\section{DESTRUCTIVE CULTURE IN SPORT}

The Talent Team and Management (i.e. upper-echelon staff) formulated a goal of a change of culture in the sport. This change was understood as a transformation of the prevailing culture in response to a growing deficiency (Mannion and Davies 2016).

\section{Implementation and Monitoring Phase}

The implementation and monitoring phase shifted the focus from describing the prevailing context to describing the culture processes. The iterative process held this critical shift together. And the Talent Team engaged in constant comparison (see Weed 2017) of new data and concepts to the understanding of the preconditions. Doing so helped expand and create analytical diversity (Smith and McGannon 2018). The practical approach was to discuss the data and analysis at monthly meetings. Constant comparison was also used to check that all insights were grounded in all parts of the analysis (Weed 2017). The shift helped analyse how a destructive culture emerged by probing under the surface of organisational life (Alvesson 2017).

\section{Reflection and Review Phase}

The last phase of the cycle entailed reflecting on and reviewing the emerging concepts. Here, we assessed the structural, process, and contextual fit (Mannion and Davies 2016). Engaging the researcher and the Talent Team in thinking theoretically helped open unique cultural nuances and insights. Both in the patterns of the process as well as between and within each phase of the study (Holt 2016). The iterative analysis showed that counter subcultures were crucial. Thus, we invited three individuals to take part in individual interviews to probe the findings from the fieldwork. One agreed to take part given the sensitive nature of engaging in disagreements and antagonism (Theoretical Sampling 3; Table 1). 


\section{DESTRUCTIVE CULTURE IN SPORT}

\section{Terminating the research enterprise.}

Interrogating for theoretical saturation was a critical task for the Talent Team. It happened as a collaborative judgment on the clear relationships between the concepts and categories from the analysis. Moreover, whether collecting new data would be counterproductive (Holt 2016). We carried out two meetings with parents of athletes in September 2018; three individual interviews in September, October, and November 2018; and one Focus Group with the Talent Team in November 2018 as a part of this process (Table 1). The last step was one meeting with three participants from Theoretical Sampling 2 (i.e. two Talent Leads and one GSO representative) in November 2018. Doing so aimed to engage more participants in the interrogation and assess the fit and relevance of the findings. The first author's direct engagement with the NGB ended in November 2018.

\section{Findings}

We propose a framework (see Figure 2) which outlines the Process of the Emergence and Perpetuation of a Destructive Culture. Preconditions and Ongoing structural conditions underpinned the dynamic process. Figure 2 shows the process of changing stages of culture. These stages included a Challenge to survival and Emergence of a destructive culture. Finally, our analysis suggested an Organisational outcome:

Perpetuation of a destructive culture. The overlapping circles denote the core concept of ongoing power relations and subprocesses of legitimising and rationalising the stigma of destructive behaviours. Power relations denote an interdependent capacity saturating the relationships between organisations (e.g. GSOs), subcultures, and individuals. It includes Systemic power and Informational power, which we will introduce in the sections below. 


\section{Preconditions}

288 We found that the sport was loosely coupled to the external context. This was the case

289 since most subcultures in the sport argued that their sport was 'special' and 'not like

290 other sports' (see Figure 2). Most participants also explained how they perceived

291 GSOs - particularly Sport England and UK Sport — as the source of earlier hardships.

292 Recent funding changes (December 2016) had necessitated retrenchment to core

293 services (i.e. membership, coach education, safeguarding, and competitions).

The NGB had reduced staff as they took immediate actions to ensure short-term survival and financial stability. Reducing the scope also required a restructuring of the talent and senior elite performance programmes. These went from full-time professional to volunteer-based services. This occurred with no NGB oversight. Instead, non-NGB individuals set up unofficial talent and senior elite initiatives.

The NGB hired new staff (i.e. the Talent Team) after receiving ring-fenced funding for talent development from Sport England in April 2017. The funding was awarded on a two-year basis with the possibility of a two-year extension in April 2019 provided the NGB met certain targets. Yet, the new staff's lack of specialised knowledge of the sport delegitimised their systemic power with subcultures. In general, the preconditions described how the changes increased uncertainty and a fragile symbiosis between subcultures. 
307 The ongoing outside structural conditions included recent global events (e.g. bullying

308 allegations and destructive culture) in sports. These events influenced the political will

\section{Ongoing structural conditions}

towards letting sports carry on without oversight. Loose coupling between this sport and outside structural conditions worked as a buffer. The primary coupling was through formal funding relationships with Sport England and UK Sport. However, the perception of these organisations as the root of many previous problems devalued their systemic power with the community. Buffering limited the influence of changing societal norms, values, and beliefs; economic and social resources; and the evolving dependency between GSOs and NGBs (see Figure 2).

The inside structural conditions were an evolving process anchored in the history of the sport. This history included antagonism from athletes, coaches, and subcultures. This antagonism had previously led to legal cases contesting decisions made by the NGB and to athletes changing nationality. It had also led to the failings of two former short-lived (sixteen months and fourteen months) talent programmes. Many stakeholders also criticised the previous performance programmes for favouritism, nepotism, and superimposing incompatible working practices on this sport (e.g. perceived Eastern European authoritarianism).

\section{Stages of a Destructive Culture}

The Preconditions and Ongoing structural conditions influenced the stages of an emerging destructive culture.

\section{A challenge to Survival or Social Position}

Systemic power relations influenced this stage. First, Sport England engaged in employing their formal authority through imposing targets and deliverables. Here,

\section{DESTRUCTIVE CULTURE IN SPORT}




\section{DESTRUCTIVE CULTURE IN SPORT}

described by a Talent Team member:

$$
\text { I just came from a meeting with Sport England. We have all these }
$$

$$
\text { targets that we basically have to live up to. But I don't know if they are }
$$

fit for the new programme because we basically just inherited them

from the old one. So, I am trying to change them. But it's a bit hard.

\section{(Field Notes, October 2017)}

Being hidebound to funding, the Talent Team experienced that Sport England used their systemic power to prescribe changes. This relationship was explained by a participant from another GSO: 'They are being pushed. You know governing bodies are being pushed by UK Coaching, by Sport England. To make sure they have these things in place...' (Lead Officer, GSO). These prescribed changes included changing normative coaching practices and more oversight of how the NGB spent their funding. GSOs shared a consensus that funding and the NGBs relationship with them could provide the Talent Team with a set of armour when negotiating changes within the sport. However, the Talent Team experienced funding as an offer they were compelled to accommodate to receive funding. Instead, the resource rigidity led to the Talent Team experiencing ambiguity between external funding restrictions and internal pressures challenging their social position.

The Talent Team limited coaches from carrying out normative practices in their efforts to comply with funding conditions. They asserted their formal authority by terminating coaches who did not readily integrate. However, most subcultures perceived this as a threat to the sport's essence and as a challenge to subcultural survival. A notable observation was that sudden radical changes worsened the symbiosis. The knock-on effect was that subcultures were destabilised further. The following is a quote 


\title{
DESTRUCTIVE CULTURE IN SPORT
}

\author{
addresses his experience of this ambiguity:
}

And after I explain to [Talent Manager] how it works in a sports life, that

the coach setup the programme. Doesn't matter what coach. Football

coach, rugby coach, [any] coach. [The coach] sets up the programme and

the one who is responsible for the whole thing like the manager, needs to

do everything to make the programme happen. (Member of Counter

\section{Subculture)}

Our analysis of systemic power indicated that it denotes a perception of an

organisation, a group or an individual's right to prescribe adaptive change or create

conditions that might warrant adaptive changes. We found that it was an enduring and

impersonal system of control. Often enacted in routines, policies, hierarchies (e.g.

performance director, talent lead, head coach), or between organisations (e.g. Sport

England and an NGB). These features made it difficult to bypass.

\section{The Emergence of a Destructive Culture}

The ambiguity between the funding conditions and the internal pressures was the starting point for a process where severe antagonism infected the negotiation of culture.

The radical changes imposed by the Talent Team led to a sense of loss of position and resource, and to behaviours to counter their perceived loss. Early signs of a destructive culture were mostly individual behaviours exhibiting open antagonism. Left unchecked these behaviours spread within and across subcultures and magnified in severity and scope:

... a lot of feedback from the community, and to start with, quite aggressive kind of assaults on us. "You just don't know what you're doing. This is rubbish. What's going on?" When we hadn't even started, which made the start quite challenging (TT2) 


\section{DESTRUCTIVE CULTURE IN SPORT}

Antagonism turned more hostile to counter the Talent Team's perceived abuse of systemic power. We found that the beneficiaries of antagonism were mainly the transgressors. Moreover, defying the Talent Team increased the transgressors' informational power as well as weakened the Talent Team's systemic power.

Antagonism increased as adverse behaviours spread to other subcultures and apprehension faded. Achieving more informational power in the culture allowed individuals to draw favourable inferences from their work. Influential transgressors or subcultures engaged in informational power to mobilise and briefly amplify their power through manipulating or coercing individuals or groups into supporting them: I was away on competition last week alone with 12 [athletes]. None of them had ever been to the talent camps. So, the talking went into that. Why they hadn't been. They just went: “[Community Leader] tells us not to go, so we don't bother" (Excerpt from Field Notes, December 2017).

At this stage, the power relations were characterised by how individuals challenged the systemic power of the NGB. Informational power was an interdependent capacity existing between individuals, groups, and organisations. It differentiates from systemic power by being relatively discrete (e.g. rarely formalised by organisational charts or policies). This feature gives it the appearance of being brief and short-term. Informational power existed tacitly between individuals. It was not a possession to be wielded. Instead, informational powers appeared in interactions to produce movement and change.

\section{Organisational Outcome - Perpetuation of a Destructive Culture}

The significant difference between this outcome and the earlier stages was that antagonism and behaviours in violation of societal norms were common in the 


\section{DESTRUCTIVE CULTURE IN SPORT}

organisational culture. Open antagonism, deception, and manipulation were routinised

responses to communications from the NGB, as evidenced by this quote from a coach:

I can help to attract the better juniors and bring in some of the topranked seniors. This will provide these juniors with an excellent

experience, which will draw them into the system. I can tell you now that as things stand the best [athletes] won't attend in September. And you'll be left with a choice of omitting them from team selection, damaging the results and alienating the [event] community. Or backing down and picking them anyway. (Excerpt from Field Notes, July 2018)

We also found that the loose coupling between this sport and other sports channelled ambiguity to the borders. This loose coupling fed an Impression of a cultural 'bubble'. Upholding this cultural bubble was critical since idiosyncratic beliefs of what was acceptable (e.g. antagonism and manipulation) buffered outside influences further. Subcultures came to see antagonism as acceptable an as successful responses to their problems.

Moreover, most stakeholders within the sport carried out antagonistic behaviours as taken-for-granted. The paradox was that we found that individuals mentioned similar behaviours from other sports as unacceptable in the light of societal norms and general standards of conduct. Yet, they did not perceive themselves as antagonistic nor destructive. The stigma of antagonistic behaviours was shadowed by the subprocesses of legitimising and rationalising destructive behaviours.

\section{Rationalising Destructive Behaviours}

The subprocess of Rationalising destructive behaviours neutralised the stigma in the cultural bubble. Rationalising allowed individuals to carry out antagonistic behaviours 


\section{DESTRUCTIVE CULTURE IN SPORT}

and distance themselves from a socially undesirable label. This worked through Denial of responsibility, Malleability of euphemistic language, and Social weighting.

\section{Denial of responsibility}

Our analysis showed that denial of responsibility worked as a rationalising strategy. Both on its own and in combination with all other strategies. The hierarchy in the NGB led lower-level employees to rationalise that it was not their responsibility to provide oversight. Furthermore, upper-level employees denied responsibility by appealing to higher loyalties (e.g. if I punish [individual] the event will terminate). Also, the insecurity of external funding led individuals to convince themselves that some behaviours were necessary 'for the good of the sport'. And punishing powerful volunteers might further fragment or disengage the community.

\section{Malleability of euphemistic language}

The malleability of language was a strategy to create perpetual uncertainty. Most individuals in this sport used the malleability of language to neutralise stigma by packaging behaviours as appropriate or less severe. They also used euphemistic language to create uncertainty around professional titles (e.g. psychologist) such as

'Talent', 'Director of Sport', and 'Performance Programme'. Doing so allowed individuals to challenge the formal authority of the Talent Team and performance pathway.

You know [community leader] calls himself Director of GB [event]? They have basically set up a competing programme under the banner of a GB Senior Programme. And they can promise all these things. But we can't. Because we have to live up to regulations. And [Sport England] 
454 Social weighting was the most popular way to neutralise stigma. It occurred daily

455 through otherwise harmless comments, such as 'He is a bit weird' and 'they are not

456 trustworthy'. Most members of the sport aimed to establish doubt or uncertainty around

457 other individuals. Doing so placed doubt at the core of negotiating culture.

458 Intensification occurred when subcultures voiced distrust over the integrity of

459 individuals who raised concern over open antagonism. Individuals reported that

460 questioning their legitimacy delegitimised their concerns.

461

462

463

464

Moreover, some individuals felt pursued: 'I feel like [individual] puts things in place to try to catch me out' (NGB personnel). Individuals also made selective social comparisons (e.g. everybody knows the former performance director was [a tyrant]).

Doing so made their behaviours seem insignificant or less socially undesirable.

\section{Legitimising destructive behaviours}

Legitimisation denotes how antagonism (e.g. manipulation, threats, or bullying) was embedded in subcultures by ignoring and denying its occurrence. This subprocess worked in two ways. First, subcultures focused on establishing doubt around the Talent Team. The influence of this was that they experienced being distanced from the rest of the NGB. This distance decreased their systemic power and ability to assert it. This process was an institutional approach to social weighting. [I] attribute most of the [fallout with NGB] to the problems that we've had with [conflict]. And that [the NGB] has given me absolutely no support. And saying that [they] would prefer to support the other person. Because they were the person who is in it for the long run. (Excerpt from Field Notes) 


\section{DESTRUCTIVE CULTURE IN SPORT}

Second, some acts lead the NGB to make it critical to update whistleblowing policies and ethical guidelines. They did so to send a signal to external stakeholders. In updating policies, the NGB created an impression of handling the emergence of antagonism. To the outside, individuals were held to the highest standards of integrity.

But antagonism was rationalised in the culture. Especially individuals holding high informational power and low substitutability could carry out increasingly antagonistic acts. The quote is evidence of how the NGB led destructive behaviours occur by ignoring or confounding the nature of the behaviours:

[Management] wanted to make clear that it was not [destructive act], and that the whole matter had been looked over by disciplinary committees ... [Management] also acknowledged that [transgressor] had done something wrong which could not be condoned. However, it was made it clear that it was not the intention to fire or relieve [transgressor] from post. (Field Notes, December 2017)

\section{Discussion}

The purpose of this study was to explore the process of how a destructive culture emerges and perpetuates in one sport in the United Kingdom. We found that antagonism and conflict in the power relations shaped the emergence of a destructive culture. Also, stigma was removed via two subprocesses. First, rationalising included using the malleability of euphemistic language to deny any responsibility and foster uncertainty. Second, legitimising denotes how subcultures institutionalised destructive behaviours. They did so by ignoring and denying the occurrence. We also found that changing influence creating ambiguity and uncertainty within the sport. 


\section{DESTRUCTIVE CULTURE IN SPORT}

As suggested by Maitland, Hills, and Rhind (2015), we have identified the organisation as a culture to examine the cultural processes. Our findings further the understanding of culture as a dynamic succession of changing events. Here, culture is temporal and contested through everyday interactions (Maitland, Hills, and Rhind 2015; Alvesson 2017). Our findings show that capturing culture over time as successive events focus ambiguity and change. Doing so also gives us a deeper understanding of the logics behind process-as-it-happens (Helin et al. 2014).

Most earlier research viewed organisational cultures through an integration perspective and cross-sectional research (Maitland, Hills, and Rhind 2015). This view assumes an implicit understanding of culture as stasis in a relatively closed system. But it does not account for how culture could move with events. How things are is how they will remain. Many definitions may alert to some kind of 'dynamic process'. Yet, asking the question: 'what is culture?' would most likely result in descriptive accounts. Gergen (2015) explains that describing or mirroring in research is subject to a receding span of application. Providing descriptions of values and beliefs in the search for the proposed ultimate source of culture-basic assumptions (see Schein 2010)—could, therefore, be limited in potential. Instead, the uptake of process in our study contributes to new ways of understanding covert organisational life (Alvesson 2017). Doing so underscores that culture is more than what is shared since it includes ambiguity and diversity (Mcdougall et al. 2017). And capturing findings along the way holds the Grounded Action method as suitable for theorising change processes.

Our findings draw attention to the dynamic succession of change. We find it appropriate to discuss our contribution through a lens of organisational change.

Cruickshank, Collins, and Minten (2014, 2015), suggests that gaining an understanding of the context underpin driving culture change. Our findings support this idea. Yet, we 


\section{DESTRUCTIVE CULTURE IN SPORT}

also found that the context relates to both preconditions and ongoing structural

conditions. Carrying out one analysis of the context before a change process might not be sufficient for organisational practitioners (Helin et al. 2014).

In the light of our study, we suggests that we can have stronger confidence in their suggestion that a change process is underpinned by ongoing power relations or 'power flows' (Cruickshank, Collins, and Minten 2014, 2015). But, our findings also suggest that the findings of Cruickshank, Collins, and Minten $(2014,2015)$ and Cole and Martin (2018) are limited since all three studies overemphasise a leader's ability to manage culture change proactively. Instead, we emphasise that power is relational.

Culture change is thus subject to ambiguous and diffuse sources (e.g. funding or antagonism). Not just leader-led.

Mannion and Davies (2016) suggest that few large, complex organisations are characterised by a single dominant culture. Likewise, we found that the organisation was a boundary of multiple subcultures. The unique feature of this organisation was how subcultures negotiated culture. We can — based on these findings - have increased confidence in the robustness of Mannion and Davies (2016). The significance of this is that it leaves cultural leaders with fever levers to control culture and produce predicted results (Alvesson 2017).

The present study provides first insights into how a culture denies and ignores the emergence of less socially desirable behaviours. Mountjoy (2018) expresses the importance of safeguarding policies and procedures to protect those working and participating in sport. Contrary to her point, we found that updating safeguarding and whistleblowing policies were perceived as a tick-box exercise. Only serving as protecting the reputation of NGBs and sports in general and reassure the public that the sport adhered to societal norms and standards. The implication is that it serves as 


\section{DESTRUCTIVE CULTURE IN SPORT}

outward communication and less as inward oversight. Thus, an ineffective approach to curb antagonism or unacceptable behaviours. Instead, our findings second the voice of six-time Olympic medallist, Aly Raisman: 'Their [USA Gymnastics] biggest priority from the beginning and still today, is their reputation' (Mountjoy 2018, 2).

Interestingly, the Duty of Care review (2017) recommends a greater emphasis on such policies. The psychological impact of this study, however, is that sports organisations should introduce wider measures to protect athletes and staff. Our findings reinforce that introducing a Sports Ombudsman to provide independent oversight and assurance that welfare is addressed should be an immediate priority (Grey-Thompson 2017). In fact, the Swedish Sports Confederation has already introduced a Sports Ombudsman in November 2018 to reinforce safe sport for children (Riksforbundet 2018).

Finally, discrediting and creating uncertainty about individuals was at the core of rationalising and neutralising antagonism. Looking beyond sports, this type of social weighting involves impugning the legitimacy of those who would raise questions about destructive working practices (Campbell and Göritz 2014; Ashforth and Anand 2003). Anand, Ashfort, and Joshi (2005) describe this as a type of rationalisation where the legitimacy of the individual/entity is made questionable. Thus, also their argument.

\section{Strengths and limitations}

A strength of this study is that it unravels how a destructive culture emerges by studying processes along the way rather than in retrospect. Doing so reinforces integrating AR and GT as a suitable method. The limitations of this study might be that sharing control over the research enterprise might threaten the technical adequacy. Here, the first-author had to honour the inputs of the participants outside just delivering data. However, the epistemology of this study is explicitly participative. In turn, we recognise the possible 


\section{DESTRUCTIVE CULTURE IN SPORT}

bias of being dependent on people (Smith and McGannon 2018). This study employed

all the core elements of GT. However, we did so in a new epistemology. Some researchers may interpret this as a limitation. On one side, Weed (2017) asserts that GT should only be used in one of the established epistemological variants (i.e. realist positivist, realist Interpretivist, or constructivist interpretivist). Yet, other studies have used GT in other epistemologies such as critical realism (Redman-Maclaren \& Mills, 2015) and feminist constructivist (Allen 2011). The critical consideration here is that the method is employed coherently with the epistemological assumptions (Sparkes and

Smith 2009). An example of how this is a strength in this study is the process of interrogating for theoretical saturation. We meet with many different stakeholders, both inside and outside the organisation, to discuss the findings as per the ethical approval of this study (Corbin and Strauss 2015). Future research could focus on scrutinising our findings of how destructive cultures emerge by employing different epistemological and methodological lenses.

\section{Concluding Thoughts}

The destructive culture in this study developed in a context of a fragile symbiosis. It was characterised by how individuals perpetuated doubt and uncertainty. They did so by packaging antagonistic behaviours in euphemistic language or denying its occurrence.

First, ambiguity arose from conflict between systemic and informational power. One example of this was how the NGB felt compelled to follow funding conditions to impose change. However, subcultures combated this through manipulating and coercing others. Second, we suggest that the lack of oversight and supervision made the sport susceptible to the normalisation of antagonism. And later the normalisation of a destructive culture. 


\section{1}

602 generalisable beyond the context of the study. Yet, the transferability of the findings is at the grace of the reader.

\section{Bibliography}

605 Allen, Mary. 2011. "Violence and Voice: Using a Feminist Constructivist Grounded 606 Theory to Explore Women's Resistance to Abuse." Qualitative Research 11 (1): 607 608 609

Protecting participants and the sport was a paramount consideration. We emphasise that we conducted the study at a specific period. And findings are not at the grace of the reader. 23-45. https://doi.org/10.1177/1468794110384452.

Alvesson, Mats. 2017. "Studying Culture in Organizations: Not Taking for Granted the Taken-for-Granted." In The Oxford Book of Management, edited by Adrian Wilkinson, Steven J. Armstrong, and Michael Lounsbury, 103-126. Oxford, UK: Oxford University Press.

Anand, Vikas, Blake E Ashforth, and Mahendra Joshi. 2005. "Business as Usual: The Acceptance and Perpetuation of Corruption in Organizations." Academy of Management Executive 19 (4): 9-23.

Arnold, Rachel, David Fletcher, and Kevin Daniels. 2013. "Development and Validation of the Organizational Stressor Indicator for Sport Performers (OSISP).” Journal of Sport and Exercise Psychology 35 (2): 180-96. https://doi.org/10.1123/jsep.35.2.180.

Ashforth, Blake E, and Vikas Anand. 2003. "The Normalization of Corruption in Organizations." Research in Organizational Behavior 25 (1): 1-52.

Brinkmann, Svend, and Steinar Kvale. 2018. Doing Interviews. 2nd ed. London: SAGE Publications Inc.

Campbell, Jamie-Lee, and Anja S. Göritz. 2014. "Culture Corrupts! A Qualitative Study of Organizational Culture in Corrupt Organizations." Journal of Business Ethics

\section{DESTRUCTIVE CULTURE IN SPORT}




\section{DESTRUCTIVE CULTURE IN SPORT}

$$
120 \text { (3): 291-311. https://doi.org/10.1007/s10551-013-1665-7. }
$$

Cole, Jason, and Andrew J Martin. 2018. “Developing a Winning Sport Team Culture: Organizational Culture in Theory and Practice.” Sport in Society 21 (8): 1204-22. https://doi.org/10.1080/17430437.2018.1442197.

Corbin, Juliet M., and Anselm Strauss. 2015. Basics of Qualitative Research Techniques and Procedures for Developing Grounded Theory. 4th ed. Thousand Oaks, CA: SAGE Publications Inc.

Costa, Arthur L, and Bena Kallick. 1993. "Through the Lens of a Critical Friend." Educational Leadership 51: 49-51.

Cruickshank, Andrew, and Dave Collins. 2012. "Culture Change in Elite Sport Performance Teams: Examining and Advancing Effectiveness in the New Era.” Journal of Applied Sport Psychology 24 (3): 338-55. https://doi.org/10.1080/10413200.2011.650819.

Cruickshank, Andrew, Dave Collins, and Sue Minten. 2013. "Culture Change in a Professional Sports Team: Shaping Environmental Contexts and Regulating Power.” International Journal of Sports Science and Coaching 8 (2): 271-90. https://doi.org/10.1260/1747-9541.8.2.271.

Cruickshank, Andrew, Dave Collins, and Sue Minten. 2014. "Driving and Sustaining Culture Change in Olympic Sport Performance Teams: A First Exploration and Grounded Theory.” Journal of Sport \& Exercise Psychology 36: 107-20. https://doi.org/10.1123/jsep.2013-0133.

Cruickshank, Andrew, Dave Collins, and Sue Minten. 2015. "Driving and Sustaining Culture Change in Professional Sport Performance Teams: A Grounded Theory.” Psychology of Sport and Exercise 20: 40-50. https://doi.org/10.1016/j.psychsport.2015.04.007. 


\section{DESTRUCTIVE CULTURE IN SPORT}

Culver, Diane M. 2012. “Qualitative Research in Sport Psychology Journals: The Next Decade 2000-2009 and Beyond." Sport Psychologist 26 (2): 261-81.

Daniels, Deborah J. 2017. "Report to USA Gymnastics on Proposed Policy and Procedural Changes for the Protection of Young Athletes.” https://usagym.org/PDFs/About USA Gymnastics/ddreport_062617.pdf.

Deakin, Hannah, and Kelly Wakefield. 2014. "Skype Interviewing: Reflections of Two PhD Researchers." Qualitative Research 14 (5): 603-16. https://doi.org/10.1177/1468794113488126.

Dick, Bob. 2007. "What Can Grounded Theorists and Action Researchers Learn from Each Other?" In The SAGE Handbook of Grounded Theory, edited by Antony Bryant and Kathy Charmaz, 398-416. Thousand Oaks, CA: SAGE Publications Inc.

Duus, Gitte, Mia Husted, Karin Kildedal, Erik Laursen, and Ditte Tofteng, eds. 2014. Aktionsforskning - En Grundbog. 1. udgave. Frederiksberg C, Danmark: Samfundslitteratur.

Fletcher, David, and Rachel Arnold. 2011. “A Qualitative Study of Performance Leadership and Management in Elite Sport.” Journal of Applied Sport Psychology 23 (2): 223-42. https://doi.org/10.1080/10413200.2011.559184.

Gergen, Kenneth J. 2015. "From Mirroring to World-Making: Research as Future Forming." Journal for the Theory of Social Behaviour 45 (3): 287-310. https://doi.org/10.1111/jtsb.12075.

Gilbourne, David, and David Richardson. 2005. “A Practitioner-Focused Approach to the Provision of Psychological Support in Soccer: Adopting Action Research Themes and Processes.” Journal of Sports Sciences 23 (6): 651-58. 


\section{DESTRUCTIVE CULTURE IN SPORT}

Gould, Daniel, Christy Greenleaf, Diane Guinan, and Yongchul Chung. 2002. “A Survey of U.S. Olympic Coaches: Variables Perceived to Have Influenced Athlete Performances and Coach Effectiveness.” The Sport Psychologist 16 (3): 229-50. https://doi.org/10.1123/tsp.16.3.229.

Greenleaf, Christy, Daniel Gould, and Kristen Dieffenbach. 2001. "Factors Influencing Olympic Performance: Interviews with Atlanta and Negano US Olympians.” Journal of Applied Sport Psychology 13 (2): 154-84. https://doi.org/10.1080/104132001753149874.

Grey-Thompson, Tanni. 2017. "Duty of Care in Sport Review.” 2017. https://www.gov.uk/government/uploads/system/uploads/attachment_data/file/610 130/Duty_of_Care_Review_-_April_2017 2.pdf.

Grix, Jonathan, and Lesley Phillpots. 2011. 'Revisiting the 'Governance Narrative': ‘Asymmetrical Network Governance' and the Deviant Case of the Sports Policy Sector." Public Policy and Administration 26 (1): 3-19. https://doi.org/10.1177/0952076710365423.

Helin, J., T. Hernes, D. Hjorth, and R Holt, eds. 2014. The Oxford Handbook ofProcess Philosophy and Organization Studies. Oxford, UK: Oxford University Press.

Henriksen, Kristoffer., Natalia. Stambulova, and K. K. Roessler. 2010a. "Successful Talent Development in Track and Field: Considering the Role of Environment.” Scandinavian Journal of Medicine and Science in Sports 20 (SUPPL. 2): 122-32. https://doi.org/10.1111/j.1600-0838.2010.01187.x.

Henriksen, Kristoffer. 2015. "Developing a High-Performance Culture: A Sport Psychology Intervention From an Ecological Perspective in Elite Orienteering." Journal of Sport Psychology in Action 6 (3): 141-53. https://doi.org/10.1080/21520704.2015.1084961. 


\section{DESTRUCTIVE CULTURE IN SPORT}

Henriksen, Kristoffer, Carsten Hvid Larsen, and Mette Krogh Christensen. 2014.

"Looking at Success from Its Opposite Pole: The Case of a Talent Development Golf Environment in Denmark." International Journal of Sport and Exercise Psychology 12 (2): 134-49. https://doi.org/10.1080/1612197X.2013.853473.

Henriksen, Kristoffer, and Natalia Stambulova. 2017. "Creating Optimal Environments for Talent Development - A Holistic Ecological Approach.” In Routledge Handbook of Talent Identification and Development in Sport, edited by Joseph Baker, Steve Cobley, Jorg Schorer, and Nick Wattie, 271-84. London, UK, UK: Routledge.

Henriksen, Kristoffer, Natalia Stambulova, and Kirsten Kaya Roessler. 2010b. "Holistic Approach to Athletic Talent Development Environments: A Successful Sailing Milieu." Psychology of Sport and Exercise 11 (3): 212-22. https://doi.org/10.1016/j.psychsport.2009.10.005.

Henriksen, Kristoffer, Natalia Stambulova, and Kirsten Kaya Roessler. 2011."Riding the Wave of an Expert : A Successful Talent Development Environment in Kayaking." The Sport Psychologist 25: 341-62.

Heron, John, and Peter Reason. 1997. “A Participatory Inquiry Paradigm.” Qualitative Inquiry 3 (3): 274-94.

Heron, John, and Peter Reason. 2006. "The Practice of Co-Operative Inquiry: Research 'With' People Rather than 'On' People.” In The Handbook of Action Research, edited by Peter Reason and Hilary Bradbury, 144-54. SAGE Publications Ltd.

Holt, Nicholas L. 2016. "Doing Grounded Theory in Sport and Exercise." In Routledge Handbook of Qualitative Research in Sport and Exercise, edited by Brett Smith and Andrew C. Sparkes, 24-36. London, UK: Routledge.

724 Houlihan, Barrie, and Mick Green. 2009. "Modernization and Sport: The Reform of 


\section{DESTRUCTIVE CULTURE IN SPORT}

Sport England and UK Sport.” Public Administration 87 (3): 678-98.

https://doi.org/10.1111/j.1467-9299.2008.01733.x.

Iphofen, Ron. 2013. "Research Ethics in Ethnography/Anthropology," 73.

http://ec.europa.eu/research/participants/data/ref/h2020/other/hi/ethics-guideethnog-anthrop_en.pdf.

Janghorban, Roksana, Robab Latifnejad Roudsari, and Ali Taghipour. 2014. "Skype Interviewing: The New Generation of Online Synchronous Interview in Qualitative Research.” International Journal of Qualitative Studies on Health and Well-Being 9 (1): 24152. https://doi.org/10.3402/qhw.v9.24152.

Kelle, Udo. 2007. "Different Approaches in Grounded Theory." In The SAGE Handbook of Grounded Theory, edited by Antony Bryant and Kathy Charmaz, 191-213. Thousand Oaks, CA: SAGE Publications Inc.

Kildedal, Karin, and Erik Laursen. 2014. "Professionsudvikling - Udvikling Af Professionel Praksis Gennem Aktionsforskning.” In Aktions Forskning En Grundbog, edited by Gitte Duus, Mia Husted, Karin Kildedal, Erik Laursen, and Ditte Tofteng, 1. udgave, 81-96. Samfundslitteratur.

King, Peter. 2012. “GBCT Review.” https://www.britishcycling.org.uk/.

Kitzinger, Jenny. 1995. “Qualitative Research: Introducing Focus Groups.” Bmj 311 (7000): 299. https://doi.org/10.1136/bmj.311.7000.299.

Krane, V., and S. M. Baird. 2005. "Using Ethnography in Applied Sport Psychology." Journal of Applied Sport Psychology 17: 87-107.

Maitland, A., L. A. Hills, and D. J. Rhind. 2015. “Organisational Culture in Sport - A Systematic Review.” Sport Management Review 18 (4): 501-16.

749 Mannion, R, and H Davies. 2016. "Culture in Health Care Organizations.” In The 


\section{DESTRUCTIVE CULTURE IN SPORT}

\section{Oxford Handbook of Health Care Management, edited by Ewan Ferlie, Kathleen} Montgomery, and Anne Reff Pedersen, First Edit, 98-116. Oxford, UK: Oxford University Press.

McCradden, Melissa D, and Michael D Cusimano. 2018. "Voices of Survivors: 'You Will Not Destroy Our Light."” British Journal of Sports Medicine 0 (0): bjsports2018-099592. https://doi.org/10.1136/bjsports-2018-099592.

Mcdougall, Michael, Mark Nesti, David Richardson, and Martin Littlewood. 2017. "Emphasising the Culture in Culture Change: Examining Current Perspectives of Culture and Offering Some Alternative Ones.” Sport \& Exercise Psychology Review 13 (1): 47-62. https://doi.org/10.1016/j.jcorpfin.2010.10.004.

Meyerson, Debra, and Joanne Martin. 1987. “Cultural Change: An Integration of Three Different Views.” Journal of Management Studies 24 (6): 623-47.

Mountjoy, Margo. 2018. “'Only by Speaking out Can We Create Lasting Change’: What Can We Learn from the Dr Larry Nassar Tragedy?" British Journal of Sports Medicine 0 (0). https://doi.org/10.1136/bjsports-2018-099403.

Pfarrer, Michael D., Katherine A Decelles, Ken G Smith, and M Susan Taylor. 2008. "After the Fall: Reintegrating the Corrupt Organization." Academy of Management Review 33 (3): 730-49. https://www.jstor.org/stable/pdf/20159433.pdf.

Phelps, Annamarie, Jude Kelly, Stuart Lancaster, John Mehrzad, and Annie Panter. 2017. "Report of the Independent Review Panel Into the Climate and Culture of the World Class Programme in British Cycling." http://www.sportsthinktank.com/uploads/cycling-independent-review.pdf.

Redman-Maclaren, Michelle, and Jane Mills. 2015. "Transformational Grounded Theory: Theory, Voice, and Action." National Health and Medical Research. http://journals.sagepub.com/doi/pdf/10.1177/160940691501400301. 


\section{DESTRUCTIVE CULTURE IN SPORT}

Riksforbundet. 2018. “Nu Öppnas Idrottsombudsman Och Visselblåsartjänst För En

$$
\text { Trygg Idrott - Riksidrottsförbundet.” } 2018 .
$$

https://www.rf.se/Nyheter/Allanyheter/nuoppnasidrottsombudsmanochvisselblasart janstforentryggidrott/.

Sbaraini, Alexandra, Stacy M. Carter, R. Evans, and Anthony Blinkhorn. 2011. "How to Do a Grounded Theory Study: A Worked Example of a Study of Dental Practices." BMC Medical Research Methodology. Vol. 11. https://doi.org/10.1186/1471-2288$11-128$.

Schein, Edgar H. 2010. Organizational Culture and Leadership. 4th ed. Hoboken, NJ: Jossey-Bass Business and Management.

Smith, Brett, and Kerry R. McGannon. 2018. "Developing Rigor in Qualitative Research: Problems and Opportunities within Sport and Exercise Psychology.” International Review of Sport and Exercise Psychology 11 (1): 101-21. https://doi.org/10.1080/1750984X.2017.1317357.

Sparkes, Andrew C, and Brett Smith. 2009. "Judging the Quality of Qualitative Inquiry: Criteriology and Relativism in Action.” Psychology of Sport \& Exercise 10: 49197. https://doi.org/10.1016/j.psychsport.2009.02.006.

Teram, Eli, Candice L Schachter, and Carol A Stalker. 2005. “The Case for Integrating Grounded Theory and Participatory Action Research: Empowering Clients to Inform Professional Practice." Qualitative Health Research 15 (8): 1129-40. https://doi.org/10.1177/1049732305275882.

The Ethics Centre. 2018. "Australian Cricket - A Matter of Balance.”

UK Sport. 2018. "2017 Culture Health Check.”

Wagstaff, Christopher R D, and Suzanna Burton-Wylie. 2018. “Organisational Culture in Sport: A Conceptual, Definitional and Methodological Review." Sport \& 
1
2

6

800

\section{DESTRUCTIVE CULTURE IN SPORT}

Exercise Psychology Review 14 (2): 32-52.

801 Weed, Mike. 2017. "Capturing the Essence of Grounded Theory: The Importance of

802 Understanding Commonalities and Variants." Qualitative Research in Sport,

1

803

Exercise and Health 9 (1): 149-56.

13

804

https://doi.org/10.1080/2159676X.2016.1251701.

805

806 
DESTRUCTIVE CULTURE IN SPORT

807 Table 1. Overview of participants

808 Figure 1. Grounded Action Cycles

809 Figure 2. Empirical model of the process of the emergence and perpetuation of

1810 destructive culture

811 
Table 1.

Overview of participants.

\begin{tabular}{|c|c|c|c|c|}
\hline Initial Sample & Group Label & $\mathbf{N}$ & Gender & Approach \\
\hline \multicolumn{5}{|l|}{ Focus groups } \\
\hline Talent Team & TT1 & 4 & 1 female, 3 males & \\
\hline \multirow[t]{2}{*}{ Athletes } & A1 & 7 & 3 females; 4 males & \\
\hline & A2 & 8 & 4 female, 4 males & \\
\hline \multirow[t]{4}{*}{ Coaches } & $\mathrm{C} 1$ & 3 & 3 males & \\
\hline & $\mathrm{C} 2$ & 3 & 1 female; 2 males & \\
\hline & $\mathrm{C} 3$ & 2 & 2 males & \\
\hline & $\mathrm{C} 4$ & 2 & 2 males & \\
\hline Parents & $\mathrm{P} 1$ & 10 & 6 females; 4 males & \\
\hline \multicolumn{5}{|l|}{ Individual Interviews } \\
\hline Assistant Talent Manager & ATM & 1 & Male & \\
\hline Youth GBR Head Talent Coach & GBR & 1 & Male & \\
\hline Talent Manager & $\mathrm{TM}$ & 1 & Male & \\
\hline Theoretical Sampling 1 & Group Label & $\mathrm{N}$ & Gender & Approach \\
\hline \multicolumn{5}{|l|}{ Focus groups } \\
\hline $\begin{array}{l}\text { Parents of athletes in underserved } \\
\text { areas }\end{array}$ & & 2 & 1 female; 1 male & \\
\hline Theoretical Sampling 2 & Group Label & $\mathrm{N}$ & Gender & Approach \\
\hline \multicolumn{5}{|l|}{ Individual Interviews } \\
\hline Talent Leads from other NGBs & & 3 & All males & Skype \\
\hline $\begin{array}{l}\text { Talented Athlete Scholarship } \\
\text { Scheme Advisor }\end{array}$ & & 1 & Male & Skype \\
\hline UK Coaching & & 1 & Male & Skype \\
\hline UK Sports & & 1 & Male & Skype \\
\hline Sport England & & 1 & Female & Skype \\
\hline English Institute of Sport & & 1 & Male & Skype \\
\hline $\begin{array}{l}\text { UK University Sports Scholars } \\
\text { Programme }\end{array}$ & & 1 & Female & Skype \\
\hline $\begin{array}{l}\text { Theoretical Sampling } 3 \\
\text { Individual Interviews }\end{array}$ & Group Label & $\mathrm{N}$ & Gender & Approach \\
\hline $\begin{array}{l}\text { Members of counter subcultures } \\
\text { Theoretical Sampling } 4\end{array}$ & Group Label & $\begin{array}{l}1 \\
N\end{array}$ & $\begin{array}{l}\text { Male } \\
\text { Gender }\end{array}$ & $\begin{array}{l}\text { Skype } \\
\text { Approach }\end{array}$ \\
\hline \multicolumn{5}{|l|}{ Focus Groups } \\
\hline $\begin{array}{l}\text { Talent Team } \\
\text { Individual Interviews }\end{array}$ & TT2 & 5 & All males & Focus Group \\
\hline Talent Manager & & 1 & Male & Skype \\
\hline Head of Coach Development & & 1 & Male & Skype \\
\hline Management & & 1 & Female & Skype \\
\hline
\end{tabular}


1. Reconnaissance Phase

Establish and understanding of the context (e.g. research environment, culture, working practices etc.)

with a view to indentifying subseqent action.

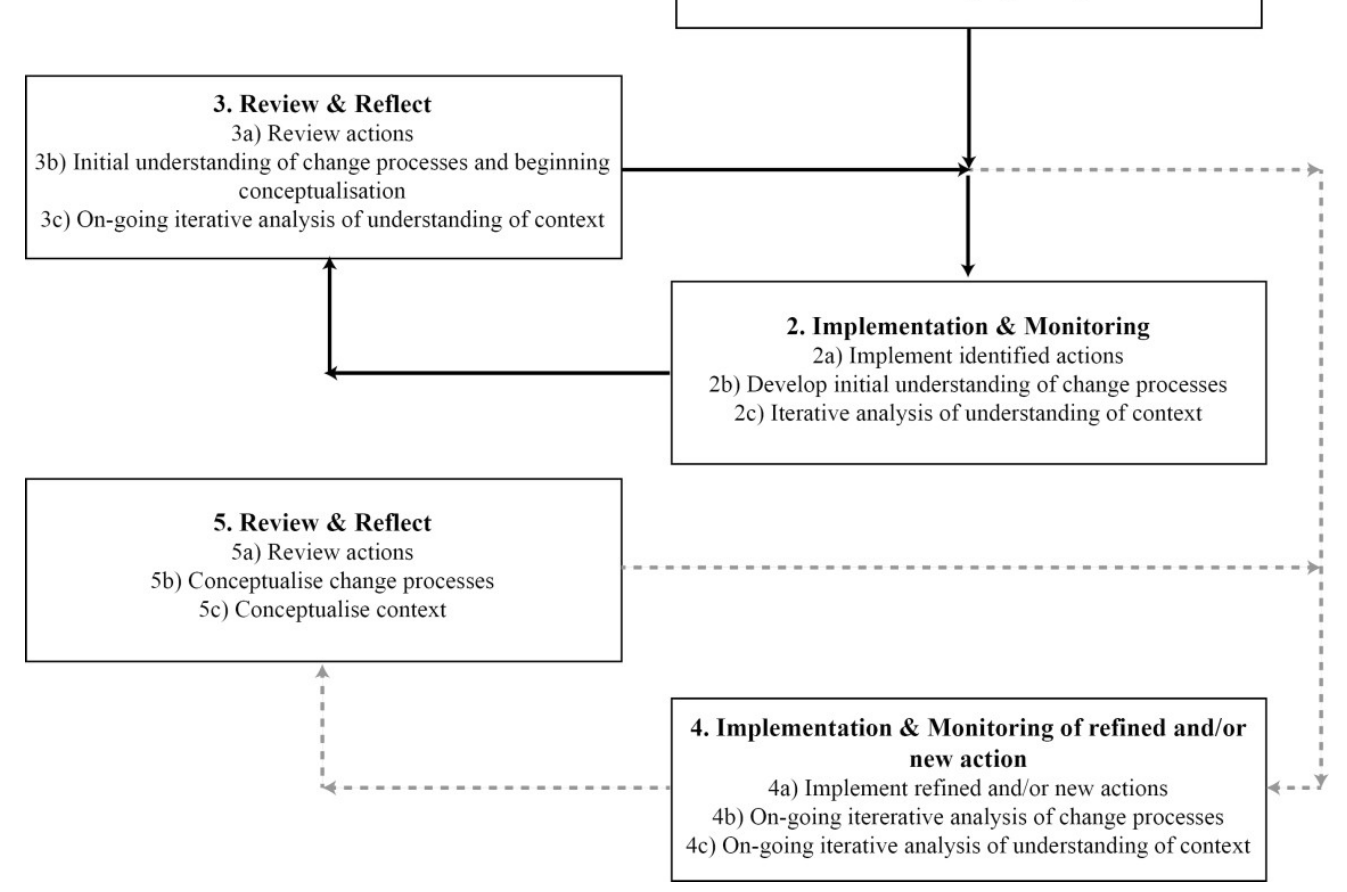

Figure 1. Grounded Action Cycles

$231 \times 180 \mathrm{~mm}$ ( $300 \times 300$ DPI) 


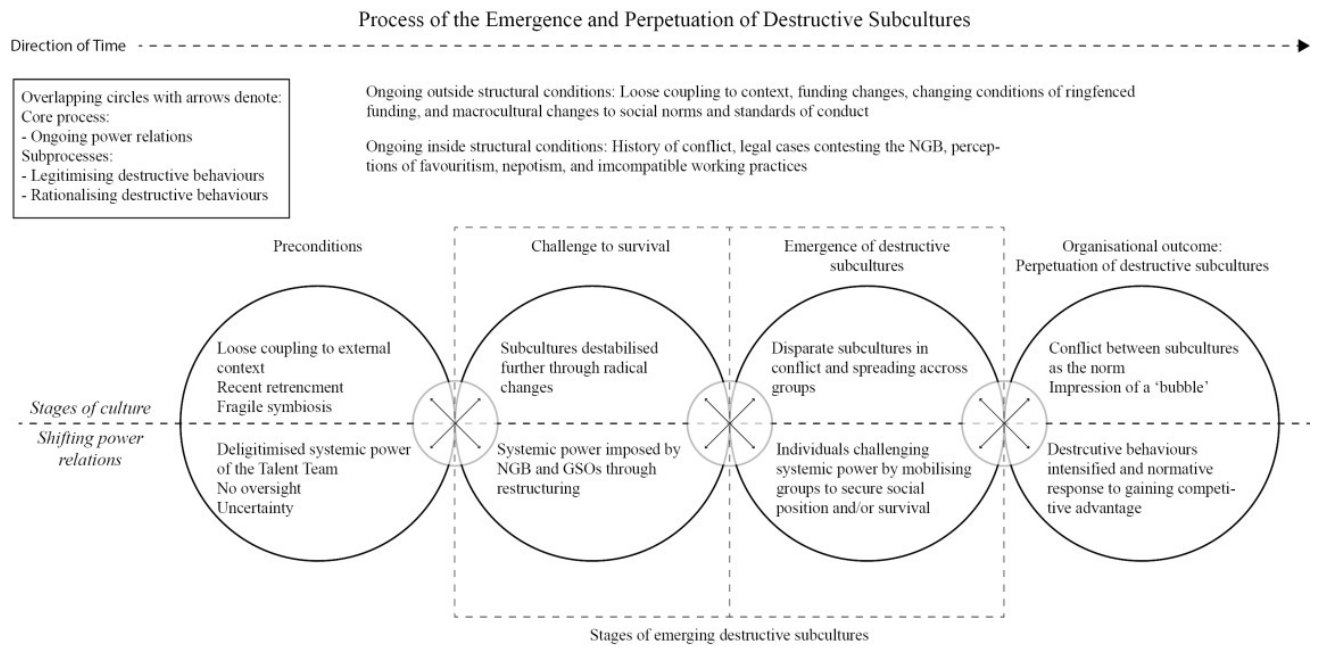

Figure 2. Empirical model of the process of the emergence and perpetuation of destructive subcultures $253 \times 125 \mathrm{~mm}(300 \times 300 \mathrm{DPI})$ 
